\title{
WEB 2.0 FOR FOSTERING STUDENTS' SOCIAL PRESENCE IN ONLINE LEARNING-BASED INTERACTION
}

\author{
Yahya M. Al-Dheleai ${ }^{1}$ iD, Zaidatun Tasir $^{2}$ iD \\ ${ }^{1}$ School of Educational Studies, Universiti Sains Malaysia (Malaysia) \\ ${ }^{2}$ School of Education, Faculty of Social Sciences and Humanities, Universiti Teknologi Malaysia (Malaysia) \\ yamohd3@gmail.com,p-zaida@utm.my
}

Received September 2018

Accepted December 2018

\section{Abstract}

Research in education confirmed that students engage in learning when they feel connected with others and when they play an active role in their learning process. Therefore; social presence (SP) considered as an important component of effective learning in both face-face and online learning environment. Therefore, this study intended to investigate students' perception about SP when using Web 2.0 tool for learning-based interaction and the difference in their perception based on gender and number of the semesters of the study. The participants of this study were 71 postgraduate students in one of the Malaysian public universities. The quantitative methods of data collection and data analysis were used in this study. Therefore, the researcher employed survey method using Online Social Presence Questionnaire (OSPQ) to collect the data. The data were analyzed using SPSS software to find mean, standard deviation of students' perception of their social presence while using Web 2.0 tool for learning-based interaction. Independent sample t-test was used to find the difference in students perception based on their gender. Moreover, One-Way ANOVA was used to find the difference in students' SP perception based on their semester of the study. The findings of this study showed that students expressed high perception about their social presence on Web 2.0 tool. Nonetheless, male students perceived higher social presence on Web 2.0 tool than female students. However, there were not significant differences in students' perception of social presence neither based on the gender difference nor on the number of the semester of the study.

Keywords - Social presence, Learning based interaction, Web 2.0.

\section{To cite this article:}

Al-Dheleai, Y.M., Tasir, Z. (2019). Web 2.0 for fostering students' social presence in online learningbased interaction. Journal of Technology and Science Education, 9(1), 13-19.

https://doi.org/10.3926/jotse.552

\section{Introduction}

The technology advancement in the last decade has changed the way of people interaction and communication. Tertiary education has massively affected by the coming of new online media which brought more alternatives to online learning. Web 2.0 and social media seen as an appropriate place where pedagogical activities may take place as they can facilitate knowledge creation, knowledge sharing and collaboration (Selwyn, 2007). Moreover, Web 2.0 technology enable users of co-creation of content with 
each other and support more social interaction in more dynamic way (Becker, 2012). However, interaction was proved to be related to social presence; as social presence increase interaction increase and vice versa (Oyarzun, 2016). Hence, students' social presence with peers and instructor found to improve overtime (Akcaoglu \& Lee, 2018). Nonetheless, the degree of social presence is based on the characteristics of the interaction medium and users' perception (Tu \& McIsaac, 2002). Hence, this study was intended to find out students' perception of social interaction as they use Web 2.0 tool for learning purpose.

\subsection{Web 2.0 as Online Learning Tools}

Several research findings showed that Web 2.0 tools can be used for learning and it can enhance learning outcomes. Selwyn (2007) for example stated that research findings from Europe, North America and Australia showed Web 2.0 tools to have the potential to enhance learning outcomes. In Australian context for example, (Bennett, Bishop, Dalgarno, Waycott \& Kennedy, 2012) highlighted that the effective use Web 2.0 increase the potential learning benefit through students content creation and sharing in particular. Moreover, a study in Malaysian context found that, Web 2.0 tools such as Facebook has the potential to facilitate online instructor roles of instructional design and organization, facilitating discourse and direct instruction (Al-dheleai \& Tasir, 2016) and to support student-student online interaction (Al-dheleai \& Tasir, 2017) which resulted greater students' academic performance. Baisley-Nodine, Ritzhaupt and Antonenko (2018) recommended researchers and teachers to use of web 2.0 or social networking tools to provide students the opportunity to master educational experience and skills. Baisley-Nodine et al. (2018) argued that the use of such tools in students' learning can help students to establish student to student social presence and community which positively contribute to their learning outcome.

Boyd (2007) attributed Web 2.0 potential to enhance education to its sociability aspects. Through sociability aspects, Web 2.0 has the ability to support learner-centered instruction through facilitating conventional interaction, social feedback, networks and relationship between users (Boyd, 2007). However, the missing part in (Boyd, 2007) sociability of Web 2.0 is social presence. Supporting social presence is considered to be an important feature of any technology to facilitate better learning. However, studies on social presence while using Web 2.0 tools for learning are still limited. Therefore, this study was intended to investigate students' social presence in learning-based interaction via Web 2.0 tool.

\subsection{Social Presence}

Social presence is considered as an important factor for online learning (Gunawardena \& Zittle, 1997) in most technology-based learning ( $\mathrm{Tu}, 2000)$. Social presence basically defined as "the degree to which a person is perceived as a 'real person' in mediated communication" (Gunawardena, 1995). Garrison, Anderson and Archer (2000) defined social presence as "the ability of participants in a community of inquiry to project themselves socially and emotionally, as 'real' people through the medium of communication being used". Moreover, social presence was defined as the perception that there is another real person taking part in the interaction (Tu \& McIsaac, 2002). Scollins-Mantha (2008) identifies social presence as being connected or engaged with others in some form of exchange. More recent study considered social presence in online learning environments as the degree to which a learner feels personally connected with other students and the instructor in an online learning community (Sung \& Mayer, 2012). In other words, social presence is the individual perception that his/her presence with a group of people is recognized, valued and respected which boost the feeling of connected to other group members.

Sung and Mayer (2012) identifies five factors that affect social presence in online education. Sung and Mayer (2012) five factors namely are social respect, social sharing, open mind, social identity and intimacy. First, social respect can be shown through instructor and learners appreciation of learners' efforts and time spent on learning activities such as posting questions, ideas, opinion or feedback via online medium. Second, instructor and students are required to share personal information, belief, values and professional interest as a way to show social sharing for the purpose of building stronger social relationship. Third, online instructors are advised to encourage an open atmosphere for learners to express their feedback 
freely and engage in critical discussion through which they can create open mind that take others' arguments and opinions positively. Next, the awareness of each learners' identity "their name or their group name" by the instructor and other learners to show they are recognized by everyone in the group and they care about his/her social identity among the group members. Finally, sharing personal experience by the instructor and other learners such as work experience allow students' to see them as a humans he/she share with them same experience. Therefore, the mentioned five factors of online social presence were seen as to foster students' feeling of being together and more connected in a way that they can provide the guidance for designing online learning system (Sung \& Mayer, 2012).

However, Sung and Mayer (2012) recommended that future studies need to examine the five factors in different age, gender, level of study, different cultural background and other online environment. Therefore, this study has intended to examine the five factors in higher education specifically master level, in Malaysian context which has different background from the context of the original study as well as different online environment which is web 2.0 tool.

\subsection{Gender and Social Presence}

The significance of the impact of the internet users' gender has different and not conclusive findings in the use of the internet research (Thayalan, Shanthi \& Paridi, 2012). The gender impact on the way people use the internet might be affected the culture, purpose of the use and the level of education. Therefore, Thayalan et al. (2012) argued gender difference place a significant influence on the behavior and the participation level of computer mediated communication CMC users. Therefore, one of the aims of the current study was to find out the impact of students' gender on their perceived social presence.

\subsection{Semester of the Study and Social Presence}

On the other side, number of the taken online courses found to have an impact of students' perceived social presence. For example, Hostetter and Busch (2006) found that higher number of online courses were related to higher perception of social presence. Similarly, Mykota (2015) reported that number of online courses taken is one of the predictors of students' social presence. Furthermore, the number of the taken online courses showed the main effect on students' social presence (Mykota, 2015). However, the question raised in this study is that what about the effect of the taken in-campus semesters on students' perception of their social presence when using Web 2.0 for learning purpose. Thus, analyzing the effect of the taken in-campus semesters was intended in this study.

\section{Objectives}

This study was designed to achieve the following objectives:

- To investigate students' perception of their online social presence while using Web 2.0 tools for online interaction.

- To identify the difference in students' perception of their online social presence based on their gender and number of the semesters of the study.

\section{Methodology}

The participants of this study were 71 master students from Educational Sciences, Mathematics and Creative Multimedia in one of Malaysian public universities. The respondents were using Web 2.0 tool for peer interaction and to interact with their instructor after the classes' time. Online Social Presence Questionnaire (OSPQ) developed by (Sung \& Mayer, 2012) was adapted to reflect the use of a new interaction medium "Web 2.0"and used as an instrument of the data collection. The questionnaire has nineteen (19) items which disseminated among five constructs. The five constructs namely are social respect (5 items), social sharing (5 items), open mind (3 items), social identity (4 items) and intimacy (2 items). Quantitative data analysis using SPSS software was employed namely Mean and Standard Deviation to find out student perception of social presence. However, the Independent Sample t-test was 
used to identify the difference in students in their perception of social presence based on their gender. Moreover, One-way ANNOVA was used to find the difference on students' perception social presence based on the number of the semesters of their study.

\section{Findings}

\subsection{Students' Perception of Social Presence}

The findings shown in table 1 indicated that students have high perception of their overall social presence when interacting with the instructors and their peer students. The analysis for each construct showed that students feeling social respect were perceived higher among the five SP factors with mean of 4.34 and SD of .472. Second highly perceived SP factor was open mind with mean of 4.24 and SD .453 followed by students' sense of social sharing factor which registered mean of 4.18 and SD of .562. However, students' have less perception of their sense of intimacy or willing to share personal stories than other factors with mean of 3.65 and SD of 1.091 .

\begin{tabular}{|c|c|c|}
\hline Factor Name & Mean & SD \\
\hline Social Respect & 4.34 & .472 \\
\hline Social Sharing & 4.18 & .562 \\
\hline Open Mind & 4.24 & .453 \\
\hline Social Identity & 4.14 & .472 \\
\hline Intimacy & 3.65 & 1.019 \\
\hline
\end{tabular}

Table 1. Students' perception of their social presence on Web 2.0

\subsection{The Difference in Students' Perception of Social Presence Based on their Gender and Semester of the Study}

\subsubsection{Perception of Social Presence Based on Gender}

The researchers conducted an independent sample t-test to find out the differences between the respondents on their perceived social presence based on their gender. Group statistics finding showed that male students reported slightly higher perception of sense of social presence (Mean $=4.29, \mathrm{SD}=.079$ ) than their counterpart female student (Mean $=4.11, \mathrm{SD}=.059)$. However, the independent sample test showed that, the difference between male and female students in their perceived social presence was not significant $(\mathrm{t}=-1.754, \mathrm{df}=69, \mathrm{p}=.084)$.

\subsubsection{Perception of Social Presence Based on the Number of the Semester of the Study}

Moreover, the researchers conducted One-Way ANOVA test to find the difference between students in their sense of social presence during online interaction based on their number of the semesters of the study. One-Way ANOVA findings indicated that there was no statistically significant difference between students in different semesters in their sense of social presence during online interaction via Web 2.0 $(\mathrm{F}(3,67)=2.289, \mathrm{p}=.086)$.

\section{Discussion and Conclusion}

Social presence as defined by (Sung \& Mayer, 2012) is students' subjective perception of connected with others in online learning environment. Therefore, the findings of this study showed students' high perception of being connected to others during online interaction via Web 2.0. In general, this study reflected that social respect, social sharing, open mind and social identity are highly valued by students and seen to be a leading factors for students' sense of presence in online interaction via Web 2.0. On the other hand, students saw intimacy as the least factor that led them to the sense of social presence.

It is the instructor role to boost students' social presence through showing appreciation to students who spend time and efforts to share ideas, point of views and encourage students to do so. The instructor also should encourage students to freely communicate with each other and with him/her as well. As a result, 
students will engage in more discussion as they feel their efforts are valued by the instructor and other participants and feel they are socially respected.

Social sharing can be also achieved through sharing and respecting others values and beliefs and providing support to students who face difficulties in their study and in their personal life as well. However, the mentioned acts will certainly lead to close relationship between instructor and students and among students and make students feel more connected. Moreover, students in this study expressed their willingness to accept others' feedback and discussion about their opinion or ideas. Surprisingly, students even welcome others to disagree with their opinion in a way that enrich the discussion and add other aspects to the discussed idea. Consequently, students showed open mind that allow critical discourse and let students freely state their feedback to facilitate cognitive interaction in online environment (Sung \& Mayer, 2012).

On the other hand, social identity is about recognizing the presence of others through greeting them, and addressing their names. Thus, students in this study expressed that they feel a sense of presence when instructor and students begin their posts with greetings. Subsequently, addressing the name reflect that the instructor and peers are aware of student's identity and this can be a fostering factor for student's sense of social presence.

High sense of safety and trust toward the instructor and other students' deepen the relationship among learning community members. Students' sense of "intimacy" or safety and trust in their learning community tend to disclose personal life stories and feel better when he/she share emotions with online learning community. In this study, students' showed less perception about revealing and sharing personal life stories. However, students' still agree that they might share their personal life stories when they feel safe and trust the instructor and peers. Therefore, instructor should encourage students to share a personal stories or feelings of their life experience which has a connection to their study and can benefit others. However, instructor and students need to be careful about sharing the sensitive personal life stories.

This study showed that gender and number of the semesters of the study has no significant effect on student perception of social presence. The absence of the difference between male and female students on their perception of social presence might be due to the reality that everyone is using technology "at least mobile phone" and most students no matter with their gender are using their personal phones and laptops for their study. Moreover, more that $90 \%$ of Malaysian students are using Web 2.0 tools where most of the respondents were female students (Tasir, Al-dheleai, Harun \& Shukor, 2011). Similarly, number of the semester of the study showed no effect on students' perception of social presence. This might be attributed to that the respondents' of this study are master student and they have the experience and used to engage in interaction with the instructors and students during their first degree.

In conclusion, students' have a high perception about social presence when using Web 2.0 for learning interaction. Students' social presence was affected by the atmosphere of the online learning environment that mostly created by the instructor. The characteristics of the online interaction medium appeared to play the secondary role in boosting students' social presence after the efforts of the instructor in this side. Therefore, the instructor role in fostering more socialized learning environment is a crucial factor followed by the online medium. As a final point, the findings of this study highlight the importance of social presence for more interactive and collaborative learning which certainly result on a better learning.

\section{Novelty of this Study}

Social presence has been the focus of many online learning researchers through using several online learning tools. However, through the intensive review of the literature, the researchers in this study found that a very limited studies that focus in examining types students' online social presence on web 2.0 tools with emphasis on the impact of students' gender and time spent in the course (semester of study) on their online social presence. Furthermore, this study is one of a few studies to investigate the affordability of 
web 2.0 tools to support high level of students' online social presence. Moreover, the findings of this study are valuable addition to online learning and web 2.0 literature. It also provides insight that may inspire teachers and students to use 2.0 tools as a medium of online interaction as it can support students' social presence which is one of the important characteristics of online learning medium.

\section{Declaration of Conflicting Interests}

The authors declared no potential conflicts of interest with respect to the research, authorship, and/or publication of this article.

\section{Funding}

The authors would like to thank the Universiti Teknologi Malaysia (UTM) and Ministry of Education (MoE) Malaysia for their support in making this project possible. This work was supported by the Fundamental Research Grant Scheme [RJI30000.7810.4F924] initiated by UTM and MoE. The authors also would like to appreciate the support provided by the Ministry of Higher Education and Scientific Research and Amran University-Yemen which contributed to the success of this work.

\section{References}

Akcaoglu, M., \& Lee, E. (2018). Using Facebook groups to support social presence in online learning. Distance Education, 39(3), 334-352. https://doi.org/10.1080/01587919.2018.1476842

Al-dheleai, Y.M. \& Tasir, Z. (2016). Facebook To Facilitate Instructor Roles In Course-Related Online Interaction: A Pilot Study. Journal of Theoretical and Applied Information Technology, 89(2).

Al-dheleai, Y.M. \& Tasir, Z. (2017). Using Facebook for the Purpose of Students ' Interaction and its Correlation with Students' Academic Performance. The Turkish Online Journal of Educational Technology, 16(4), 170-178. Available at: http://www.tojet.net/articles/v16i4/16416.pdf

Baisley-Nodine, E., Ritzhaupt, A.D., \& Antonenko, P.D. (2018). Exploring social presence within an online course using Twitter. E-Learning and Digital Media, 15(5), 235-253.

https://doi.org/10.1177/2042753018786004

Becker, D.H. (2012). Online Social Interaction, Web 2.0 and Social Presence: a Case Study. A Dissertation Submitted for the degree of Doctor of Education in Curriculum and Instruction Northern Arizona University.

Bennett, S., Bishop, A., Dalgarno, B., Waycott, J., \& Kennedy, G. (2012). Implementing Web 2.0 technologies in higher education: A collective case study. Computers \& Education, 59, 524-534. https://doi.org/10.1016/j.compedu.2011.12.022

Boyd. D. (2007). The Significance of Social Software. In T. N. Burg \& J. Schmidt (Eds), BlogTalks Reloaded: Social Software Research \& Cases (15-30). Norderstedt, Germany: Books on Demand.

Garrison, D.R., Anderson, T., \& Archer, W. (2000). Critical Inquiry in a Text-Based Environment: Computer Conferencing in Higher Education. The Internet and Higher Education, 2, 87-105. https://doi.org/10.1016/S1096-7516(00)00016-6

Gunawardena, C.N. (1995). Social Presence Theory and Implications for Interaction and Collaborative Learning in Computer Conferences. International Journal of Educational Telecommunications, 1, 147-166.

Gunawardena, C.N., \& Zittle, F.J. (1997). Social presence as a predictor of satisfaction within a computer-mediated conferencing environment. American Journal of Distance Education, 11(3), 8-26. https://doi.org/10.1080/08923649709526970 
Hostetter, C., \& Busch, M. (2006). Measuring Up Online: The Relationship between Social Presence and Student Learning Satisfaction. Journal of Scholarship of Teaching and Learning, 6(2), 1-12.

Mykota, D.B. (2015). The influence of learner characteristics on social presence. Procedia - Social and Behavioral Sciences, IETC, 176, 627-632. https://doi.org/10.1016/j.sbspro.2015.01.520

Oyarzun, S.E.A. (2016). Effects of Learner-to-Learner Interactions on Social Presence, Achievement and Satisfaction. A Doctoral Dissertation Submitted for the Degree of Doctor of Education in Curriculum and Instruction Old Dominion University.

Scollins-Mantha, B. (2008). Cultivating social presence in the online learning classroom: A literature review with recommendations for practice. International Journal of Instructional Technology \& Distance Learning, 5(3), $1-15$.

Selwyn, N. (2007). Web 2.0 applications as alternative environments for informal learning-a critical review. In Paper for CERI-KERIS International Expert Meeting on ICT and Educational Performance, 16, 17.

Sung, E., \& Mayer, R.E. (2012). Computers in Human Behavior Five facets of social presence in online distance education. Computers in Human Behavior, 28(5), 1738-1747.

https://doi.org/10.1016/j.chb.2012.04.014

Tasir, Z., Al-dheleai, Y.M.H., Harun, J., \& Shukor, N.A. (2011). Students' Perception towards the Use of Social Networking as an e- learning Platform. In 10th WSEAS International Conference on Education and Educational Technology, Penang: Malaysia, 70-75.

Thayalan, X., Shanthi, A., \& Paridi, T. (2012). Gender Difference in Social Presence Experienced in e-Learning Activities. The 3rd International Conference on E-Learning ICEL2011, Bandung, Indonesia, 67, 580-589. https://doi.org/10.1016/j.sbspro.2012.11.363

Tu, C.H., \& McIsaac, M. (2002). The Relationship of Social Presence and Interaction in Online Classes. The American journal of distance education, 16(3). https://doi.org/10.1207/S15389286AJDE1603_2

Tu, C.H. (2000). On-line learning migration: From social learning theory to social presence theory in a CMC environment. Journal of Network and Computer Applications, 23(1), 27-37.

https://doi.org/10.1006/jnca.1999.0099

Published by OmniaScience (www.omniascience.com)

Journal of Technology and Science Education, 2019 (www.jotse.org)

(c) (i) (8)

Article's contents are provided on an Attribution-Non Commercial 4.0 Creative commons International License.

Readers are allowed to copy, distribute and communicate article's contents, provided the author's and JOTSE journal's names are included. It must not be used for commercial purposes. To see the complete licence contents, please visit https://creativecommons.org/licenses/by-nc/4.0/. 